\title{
Genetic analysis of ten polymorphic enzyme loci in Littorina saxatilis (Prosobranchia: Mollusca)
}

R. D. Ward, ${ }^{*}$ T. Warwick $\dagger$ and A. J. Knight*

\author{
* Department of Human Sciences, Environmental \\ Biology Unit, Loughborough University, \\ Loughborough, Leicestershire, LE11 3TU, U.K. \\ † Department of Zoology, University of Edinburgh, \\ West Mains Road, Edinburgh, EH9 3JT, U.K.
}

\begin{abstract}
Electrophoretic surveys of natural populations have shown Littorina saxatilis to be variable at many enzyme loci. Laboratory breeding experiments, which involved the phenotypic examination of selected parental pairs and their offspring, confirmed, for ten loci, that this variation results from the segregation of codominant alleles. The loci studied were Mpi, Pgi, Pgm-1, Pgm-2, Aat-1, Aat-2, Ap-2, Lap-1, Odh and Idh-2. Certain pairs of loci showed evidence of weak linkage; no cases of strong linkage were detected. Crosses between male $L$. saxatilis and female $L$. arcana produced viable offspring with normal segregation of parental alleles. Attempts at the reciprocal cross have so far proved unsuccessful.
\end{abstract}

\section{INTRODUCTION}

In recent years, several papers have been published concerning the extent of genetic differentiation within and between populations of several species of the genus Littorina (e.g., Snyder and Gooch, 1973; Berger, 1977; Ward and Warwick, 1980; Wilkins and O'Regan, 1980; Mastro et al., 1982; Moyse et al., 1982; Janson and Ward, 1984; Ward and Janson, 1985), a genus which comprises an important group of marine intertidal molluscs. In these studies, the genetic nature of the observed enzyme variation has been inferred, explicitly or implicitly, either by comparison with zymogram patterns of other animal species where formal breeding studies have been carried out or by comparison of phenotype distributions with the genotype distributions expected for genes in Hardy-Weinberg equilibria. Although such assumptions of Mendelian inheritance almost always prove well-founded, post-translational modification may sometimes produce enzyme variability that can be mis-scored as genetic variation. Hence, where possible, it is wise to confirm the validity of any genetic interpretations.

In the present paper, we present data from laboratory breeding experiments using $L$. saxatilis $(=L$. rudis) and 10 polymorphic loci which show that for these loci previously held genetic interpretations are indeed correct. The loci considered are mannose phosphate isomerase $(\mathrm{Mpi})$, phos- phoglucose isomerase (Pgi), phosphoglucomutases 1 and 2 (Pgm-1, Pgm-2), aspartate aminotransferases 1 and 2 (Aat-1, Aat-2), aminopeptidase-2 (Ap-2), leucine aminopeptidase-1 (Lap-1), octanol dehydrogenase (Odh) and isocitrate dehydrogenase-2 (Idh-2). We have also looked for evidence of linkage between many of these pairs of loci. Esterase variation is not considered in the present paper; here patterns are complex and, although clearly inherited, a final genetic model has yet to be formulated. Two of the successful crosses were between males of $L$. saxatilis and females of the closely related species L. arcana, and one cross was between a female $L$. saxatilis tenebrosa $(=L$. tenebrosa) and a male L. saxatilis.

Similar, although less extensive, breeding experiments have been carried out in a few other molluscan species such as the marine bivalves $\mathrm{Pec}$ ten maximus (Beaumont et al., 1986), Mytilus edulis (Hvilsom and Thiessen, 1984), and Mercenaria mercenaria (Adamkewicz et al., 1984), and the terrestrial gastropod Cepeae nemoralis (Brussard and McCracken, 1974; Oxford, 1975; Johnson, 1979).

\section{MATERIALS AND METHODS}

Immature females, most of whom were taken from wild populations although some were laboratory 
raised, were paired with wild-caught males, and the pairs isolated until live young were seen. Most crosses were between pairs of Littorina saxatilis, although some were between $L$. arcana females and $L$. saxatilis males. A full description of the breeding technique is given by Warwick (1983). When sufficient live young were seen, often after repeated matings, the parents were sacrificed and screened for electrophoretically detectable enzyme variation using the methods of Ward and Warwick (1980). If the presumed parental genotypes were such that screening of the offspring would provide useful information, individuals of the $F 1$ generation were reared to a size of $2 \cdot 5-4 \cdot 0 \mathrm{~mm}$ and then electrophoresed. Each animal was homogenised in $25 \mu \mathrm{l}$ of $0.2 \mathrm{M}$ Tris- $\mathrm{HCl}, p \mathrm{H} 8 \cdot 0$, providing sufficient extract for at least nine enzymes to be screened if desired. Locus and allele designations follow Ward and Warwick (1980) and Janson and Ward (1984).

\section{RESULTS}

The sources of animals used in the crosses are given in table 1. Many more crosses were established than indicated here, but some failed to produce offspring and in some others the parental genotypes proved insufficiently informative to merit screening of the progeny.

Littorina saxatilis is ovoviviparous, and laboratory crosses within this species resulted, as expected, in females producing live young, "crawlaways". L. arcana is oviparous, laying egg masses from which the crawlaways emerge, and it is interesting to note that in the laboratory, female arcana will mate with male saxatilis and produce egg masses and viable offspring. The progeny of two such crosses, numbers 1211 and 1625, are analysed here. The reciprocal cross has repeatedly failed to produce viable offspring. Crosses between pairs of $L$. arcana, although not described in the

Table 1 Sources and species of animals used in breeding experiments

\begin{tabular}{|c|c|c|}
\hline Cross & Source & Species \\
\hline \multirow[t]{2}{*}{872} & I Loch Bee, South Uist, Scotland & "tenebrosa" \\
\hline & O Oban a'Chlachain, North Uist, Scotland & saxatilis \\
\hline \multirow[t]{2}{*}{1072} & Spiggie Bay, Shetland Isles & saxatilis \\
\hline & o Aberlady (salting), East Lothian, Scotland & saxatilis \\
\hline \multirow[t]{2}{*}{1080} & \& Lawrencetown beach, Nova Scotia, Canada & saxatilis \\
\hline & o Aberlady (salting), East Lothian, Scotland & saxatilis \\
\hline \multirow[t]{2}{*}{1111} & \& Spiggie Bay, Shetland Isles & saxatilis \\
\hline & Roxburgh Hotel (wall), Dunbar, Scotland & saxatilis \\
\hline \multirow[t]{2}{*}{1114} & I The Fleet at Abbottsbury, Dorset, England & saxatilis \\
\hline & o Roxburgh Hotel (beach), Dunbar, Scotland & saxatilis \\
\hline \multirow[t]{2}{*}{1135} & \& Oban a'Chlachain, North Uist, Scotland & saxatilis \\
\hline & o Roxburgh Hotel (wall), Dunbar, Scotland & saxatilis \\
\hline \multirow[t]{2}{*}{1211} & o Roxburgh Hotel (wall), Dunbar, Scotland & arcana \\
\hline & o Newford Island, St. Mary's, Scilly Isles, England & saxatilis \\
\hline \multirow[t]{2}{*}{1625} & q Roxburgh Hotel. (wall), Dunbar, Scotland & arcana \\
\hline & o Marine Villa, Dirleton (beach), Scotland & saxatilis \\
\hline 1686 & + , o Seacliff (beach), North Berwick, Scotland & saxatilis \\
\hline \multirow[t]{2}{*}{1698} & o East Fleet at Moonfleet, Dorset, England & saxatilis \\
\hline & o Dale Point, Pembrokeshire, Wales & saxatilis \\
\hline 1913 & ${ }^{\text {t }}$ laboratory raised from Davis Strait, Canada & saxatilis \\
\hline \multirow[t]{2}{*}{1918} & o Oban a'Chlachain, North Uist, Scotland & saxatilis \\
\hline & o Aberlady (salting), East Lothian, Scotland & saxatilis \\
\hline \multirow[t]{2}{*}{1926} & o Davis Strait, Canada & saxatilis \\
\hline & Aberlady (salting), East Lothian, Scotland & saxatilis \\
\hline 1952 & q, o Village Bay, Hirta, St. Kilda, Scotland & saxatilis \\
\hline \multirow[t]{2}{*}{1926} & $q$ Davis Strait, Canada & saxatilis \\
\hline & Aberlady (salting), East Lothian, Scotland & saxatilis \\
\hline \multirow[t]{2}{*}{1960} & \& Newford Island, St. Mary's Scilly Isles, England & saxatilis \\
\hline & o Penzance (beach), Cornwall, England & saxatilis \\
\hline 2429 & $q$, o Marine Villa, Dirleton (beach), Scotland & saxatilis \\
\hline \multirow[t]{2}{*}{2451} & on $F 1$ progeny from cross 1879 & saxatilis \\
\hline & t Village Bay, Hirta, St. Kilda, Scotland & saxatilis \\
\hline
\end{tabular}


present article, have been carried out in the laboratory, and viable egg masses are produced (Warwick, 1983, and unpublished observations). One cross (872) was between a female of the tenebrosa variety and a typical male saxatilis. Although it has been suggested that the form tenebrosa might be a distinct species within the saxatilis complex (e.g., Fretter and Graham, 1980; Smith, 1982), recent morphological and genetical analyses indicate that it is best thought of as an ecotype of $L$. saxatilis (Janson and Ward, 1985).

\section{Segregation of alleles at single loci}

Breeding data are given in tables 2-6. In these tables, the identification number of the cross, parental genotypes, numbers and genotypes of offspring scored, fits to Mendelian expectations, and numbers of contaminants, are given.

Contaminants are those individuals in the analysed progeny that had genotypes inconsistent with the parental genotypes at one or more of the loci scored in that progeny set. Progeny were normally scored for between five and seven loci, including the highly polymorphic esterases, and generally the contaminants had inconsistencies at two or more of these loci. Such aberrant individuals are much more readily explained by contamination than by high mutation rates or gene conversion events. The source of this contamination is not known for certain, but in the rearing of the progeny algal-covered pebbles are taken from the sea shore to act as a food source (Warwick, 1983). These pebbles were carefully inspected and any lit- torinids detected removed, but it is possible that a few juveniles were occasionally transferred from the shore into the culture dishes. This contamination rate is low: for example, in the $M p i$ crosses (table 2), a total of 924 juveniles were scored of which 12 were classified as contaminants $(1.30$ per cent) and 912 as true offspring. For other loci, the contamination rate was frequently below 1 per cent.

With respect to $\mathrm{Mpi}, 13$ crosses were analysed (table 2). In previous population surveys (e.g., Ward and Warwick, 1980; Ward and Janson, 1985; Janson, 1985), three alleles have been identified at the $M p i$ locus, viz., $M p i^{120}, M p i^{100}$ and $M p i^{75}$, but it has been noted that the $M p i^{120}$ allele is a compound allele comprising two alleles of similar mobility that cannot always be unambiguously distinguished (Janson and Ward, 1984). In the parents and progeny examined in the breeding experiments, we were able to distinguish these two alleles, which are designated here $M p i^{120}$ and $M p i^{115}$. All four alleles behave as true Mendelian genes, and progeny numbers of all crosses accorded with Mendelian expectations.

Data for the Pgi locus are presented in table 3. Again, we have previously noted that the allele we commonly term $P g i^{100}$ is a compound allele (Janson and Ward, 1984), and in cross 872 we were able to distinguish the two alleles, here designated $P g i^{100}$ and $P g i^{98}$. Nine of ten crosses produce progeny in accord with Mendelian expectations, but cross 1918 showed a significant deviation $(P=$ 0.027 ). Here, observed (and expected) progeny numbers were $77(92) P g i^{100} / P g i^{100}$ and $107(92)$

Table 2 Segregation of alleles at the Mpi locus

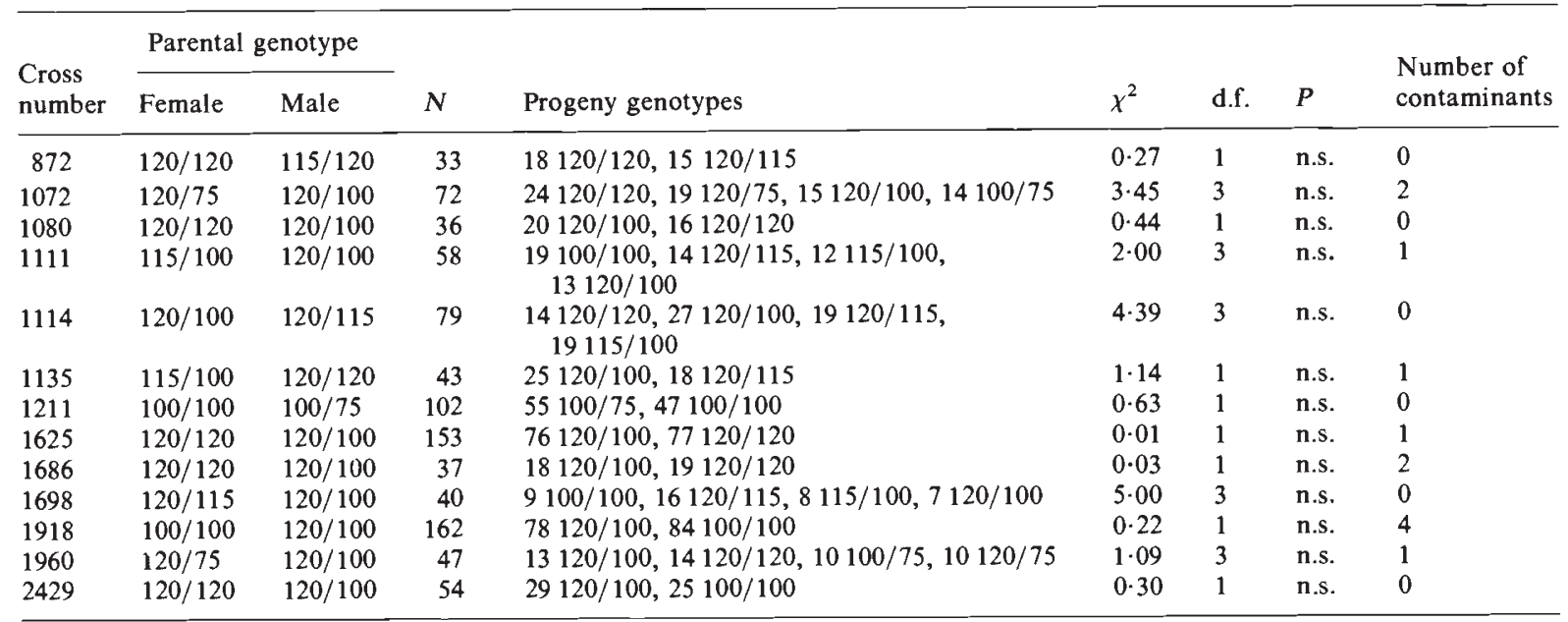


Table 3 Segregation of alleles at the Pgi locus

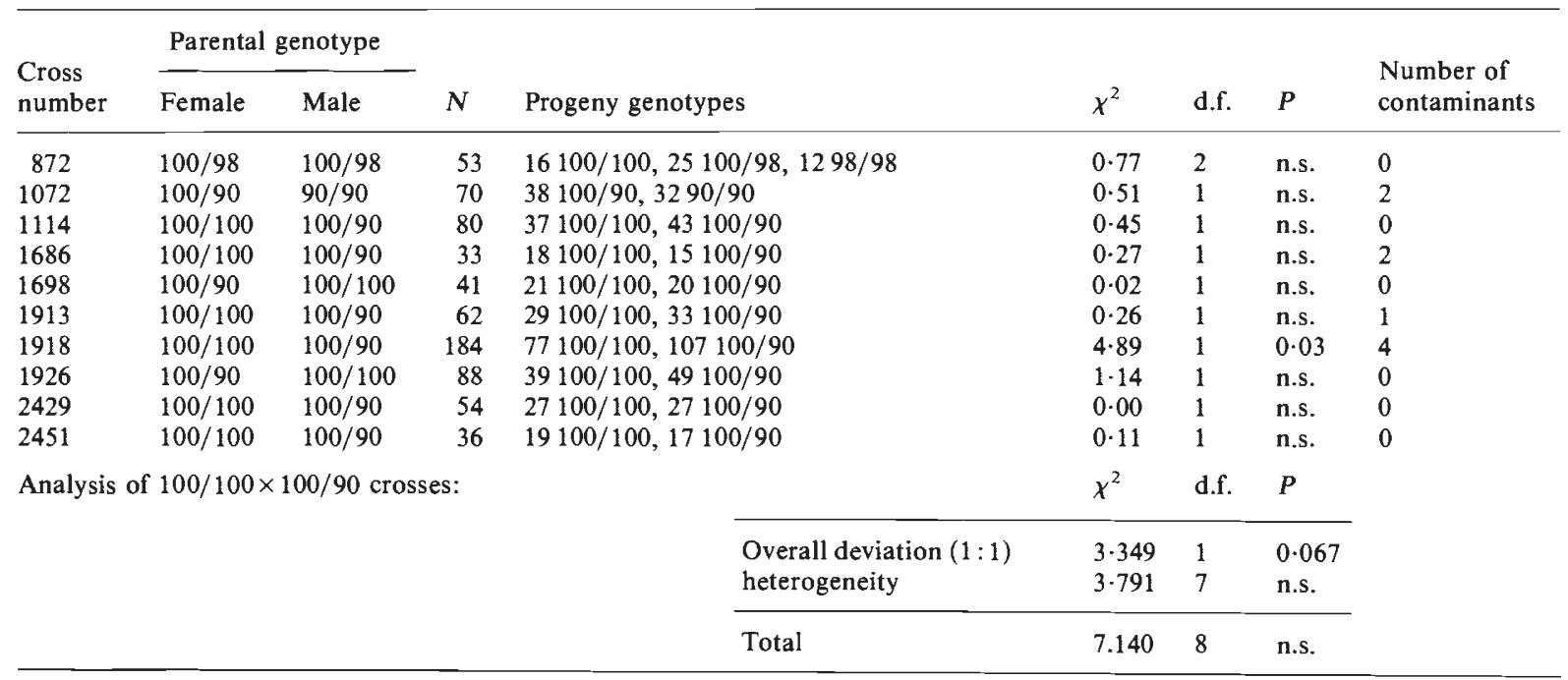

$P g i^{100} / P g i^{90}$, a surplus of heterozygotes. If progeny from all like crosses $\left(P g i^{100} / P g i^{100} \times P g i^{100} / P g i^{90}\right)$ are pooled, a total of $267 P g i^{100} / P g i^{100}$ and 311 $P g i^{100} / P g i^{90}$ are observed, a distribution not significantly different from the expected $1: 1$ ratio at the 5 per cent level $(P=0 \cdot 067)$, and there is no significant heterogeneity between crosses (table 3 ). Thus it seems likely that the heterozygote excess observed in the progeny of cross 1918 is a sampling artefact, and does not represent an increase in viability of the heterozygous genotype.

Data for the Pgm-1 and Pgm-2 loci are presented in table 4. A third locus, Pgm-F, is frequently observed in natural populations (Janson and Ward, 1984), but the products of this locus are too weak to score in laboratory reared juveniles. Eight crosses were analysed for the Pgm-1 locus and eleven for $P g m$-2. All progeny ratios accorded with

Table 4 Segregation of alleles at the Pgm-1 and Pgm-2 loci

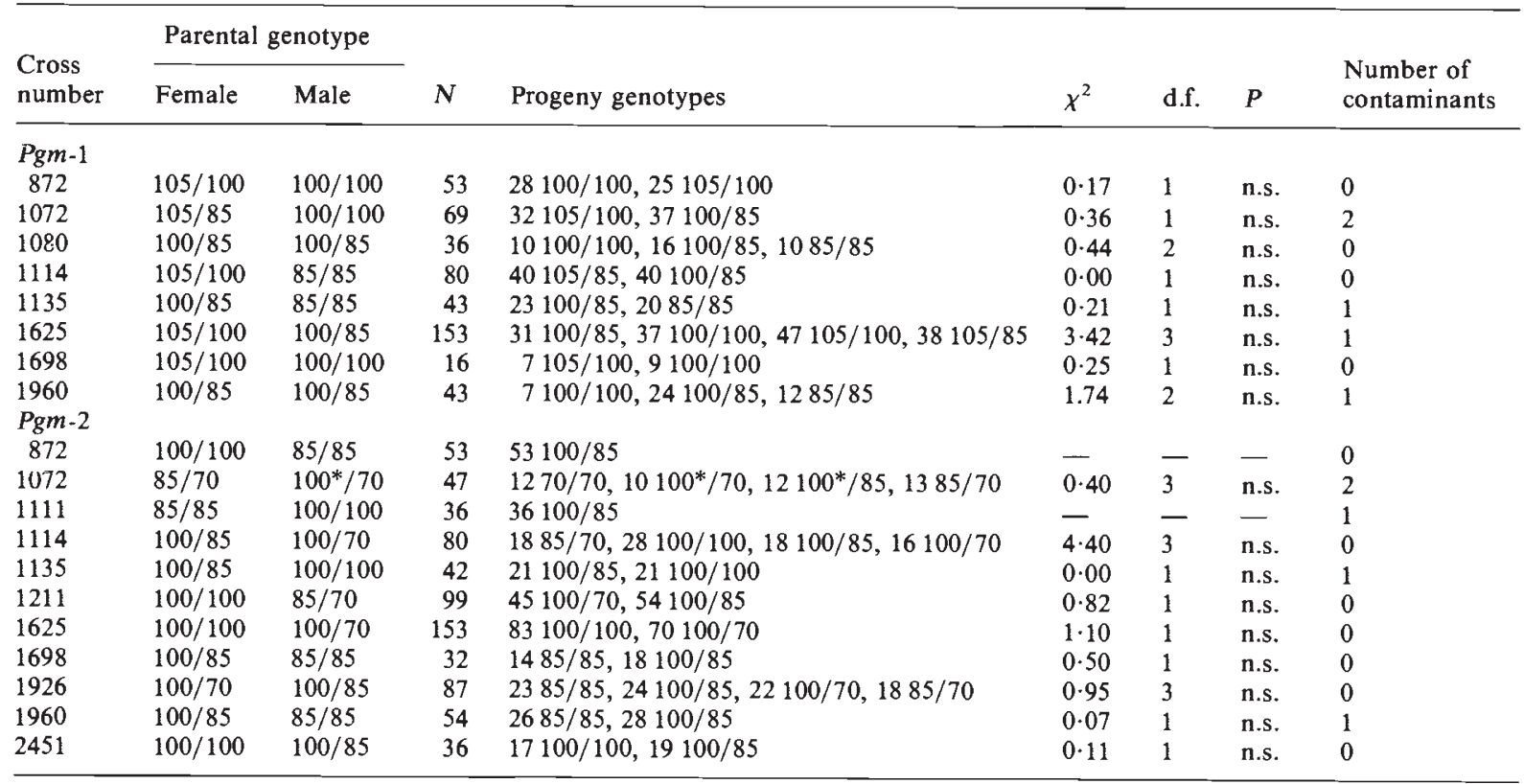

$\left(P g m-2100^{*}\right.$ : a low activity allele) 
Table 5 Segregation of alleles at the Aat-1, Aat-2, Ap-2, Lap-1, Odh and Idh-2 loci

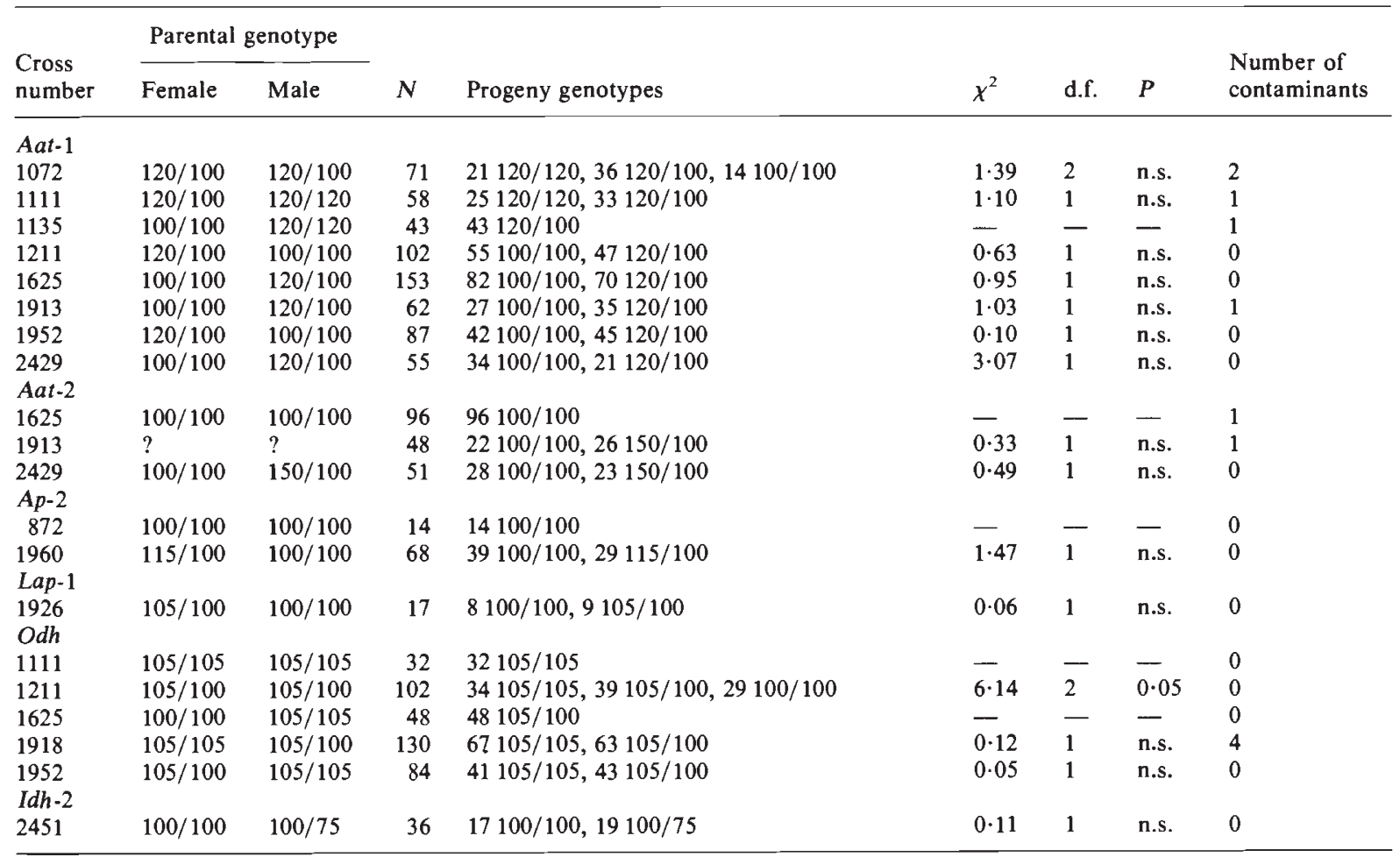

Mendelian expectations. Cross 1072 is particularly interesting with respect to the $P g m-2$ locus. The male parent was heterozygous for the $P g m-2^{85}$ allele and a low activity $P g m-2^{100}$ allele, producing a markedly asymmetrical two banded phenotype. This low activity allele was inherited and expressed as such by the progeny. It appears therefore that

Table 6 Deviations of observed heterozygosity from expected heterozygosity among the offspring of segregating crosses

\begin{tabular}{lrrr}
\hline Locus & $N$ & \multicolumn{1}{l}{} & $D$ \\
\hline Mpi & 12 & -0.0038 & -0.0094 \\
Pgi & 10 & 0.0274 & 0.0670 \\
Pgm -1 & 6 & -0.0160 & 0.0036 \\
Pgm -2 & 8 & -0.0334 & -0.0376 \\
Aat -1 & 7 & -0.1200 & -0.0238 \\
Aat -2 & 2 & -0.0074 & -0.0101 \\
Ap-2 & 1 & -0.1471 & -0.1471 \\
Lap-1 & 1 & 0.0588 & 0.0588 \\
Odh & 3 & -0.0346 & -0.0523 \\
Idh-2 & 1 & 0.0556 & 0.0556 \\
\hline
\end{tabular}

$N=$ number of segregating crosses. $\bar{D}=$ mean of the $N$ values of $D$ where $D=(H$ ob $-H \exp ) / H \exp$ and where $H$ ob and $H$ exp are the numbers of heterozygotes observed and expected respectively in each cross. $D$ (pooled) = value of $D$ calculated from the pooled numbers of heterozygotes over every cross at that locus. there is genetically determined activity variation within the $P g m-2^{100}$ allele.

Eight crosses were analysed for Aat-1 (table 5 ), and in each case, progeny numbers accorded with Mendelian expectations. With respect to Aat2 , progeny were observed to be segregating in a cross (1913) whose parents had not, unfortunately, been scored for this locus. However, these progeny segregated in a $1: 1$ ratio, and it seems likely that they resulted from an Aat $-2^{100} / A a t-2^{100} \times$ Aat $-2^{100} /$ Aat $-2^{115}$ cross. Progeny analysis of a later cross whose parents had been typed (cross 2429) showed normal segregation.

Single crosses segregating for alleles at the $\boldsymbol{A p}$ 2, Lap-1 and Idh-2 loci were scored, and progeny numbers accorded with expectations (table 5).

Three crosses were segregating for alleles at the Odh locus (table 5) and progeny crosses in two of these accorded with expectation. However, in the remaining cross (1211), a just significant deviation was observed $(P=0.046)$. Here, the two parents were both of the $O d h^{100} / O d h^{105}$ genotype, and the progeny numbers (with expected values) were as follows: $29(25 \cdot 5) \quad O d h^{100} / O d h^{100}, 39(51)$ $O d h^{100} / O d h^{105}, 34(25 \cdot 5) \quad O d h^{105} / O d h^{105}$. This deviation may have arisen because the male parent had an abnormally low activity $O d h^{100}$ allele, so 
that some $O d h^{100} / O d h^{105}$ heterozygotes may have been mistakenly scored as $O d h^{105} / O d h^{105}$ homozygotes, or it might simply have arisen through sampling error.

There is no indication of a general excess of homozygous or heterozygous individuals amongst the progeny of segregating crosses. This data is summarised in table 6 . The total observed and expected numbers of heterozygotes and homozygotes respectively are 1937 and $1947 \cdot 25$, and 1626 and $1615 \cdot 75$. These differences are non-significant $\left(\chi_{1}^{2}=0 \cdot 119, P>0.05\right)$.

\section{Linkage relationships}

Linkage relationships between pairs of loci could be examined in two types of crosses: (a) where one parent was heterozygous for the two loci in question and the other parent homozygous, and (b) where one parent was heterozygous for the two loci and the other parent differently heterozygous at one locus and homozygous at the other.

\section{Type 1:}

e.g., Cross $1072 q$ Pgi 100/90 Pgm-1 105/85× o Pgi 90/90 Pgm-1 100/100

Set A Pgi 100/90 Pgm-1 105/100, Pgi 90/90 Pgm-1 85/100.

Set B Pgi 100/90 Pgm-1 85/100, Pgi 90/90 Pgm-1

Pgm-1 105/100.

If $P g i$ and $P g m-1$ were linked, and if in the female parent the $P g i^{100}$ and $P g m-1^{105}$ alleles were in coupling, then the first two genotype classes (Set A) would be the parental types, and the second two genotypes (Set B) would be recombinants. Since the animals used in these crosses have come from wild populations and are of unknown linkage phase, we test for linkage by comparing the total number in set $\mathrm{A}$ with the total number in set $\mathrm{B}$, producing a chi-square with a single degree of freedom. In this cross, the total chi-square for a $1: 1: 1: 1$ segregation has three degrees of freedom.

\section{Type 2:}

e.g., Cross 1072 Pgi + 100/90 Mpi 120/75× ð Pgi 90/90 Mpi 120/100

Set A Pgi 100/90 Mpi 120/120,

Pgi 100/90 Mpi 120/100,

Pgi 90/90 Mpi 120/75,

Pgi 90/90 Mpi 100/75.
Set B Pgi 100/90 Mpi 120/75,

Pgi 100/90 Mpi 100/75,

Pgi 90/90 Mpi 120/120,

Pgi 90/90 Mpi 120/100.

Again, the test for linkage is to compare the total number in set $A$ with the total number in set $\mathbf{B}$, to give a chi-square with one degree of freedom, and the total chi-square for a $1: 1: 1: 1: 1: 1: 1: 1$ segregation has seven degrees of freedom.

For convenience, we have designated the most populous set as set $\mathrm{A}$ in all our crosses.

Five loci (Pgi, Mpi, Pgm-1, Pgm-2, Aat-1) were studied for all possible pairwise linkage comparisons, and the remaining five loci ( $A p$ 2, Odh, Lap-1, Aat-2 and Idh-2) enabled some additional comparisons to be made. A summary of results is provided in table 7 , with a fuller presentation in the Appendix.

Of the five loci that could be studied for all possible comparisons, only the $\mathrm{Mpi}$ and Aat-1 loci gave results indicative of loose linkage. The three crosses gave linkage chisquare values of $6.90(P=0.009), 1.68(P=$ $0 \cdot 195)$, and $1.85(P=0 \cdot 174)$ respectively, summing to 10.43 ( 3 d.f., $P=0.015$ ). The recombination fraction, assuming the set A individuals are the parental types, is 0.41 $(109 / 264)$. Unfortunately, since we cannot be certain that the set $\mathrm{A}$ individuals are parental types, this recombination fraction must be regarded as provisional, and we cannot partition the summed chi-square into deviation and heterogeneity components.

With respect to the $M p i: P g i$ and $M p i$ : Pgm-1 locus pairs, one out of six and one out of five progeny sets respectively gave significant linkage chi-square values, but for both pairs of loci the summed chi-square values are non-significant $\left(\chi^{2}=11 \cdot 58,6\right.$ d.f., $P=0.07$, and $\chi^{2}=7.09$, 5 d.f., $P=0.214$ ). Three further pairs of loci showed some signs of linkage (Pgi:Lap-1, Pgi:Odh, Aat$1: O d h)$ but in each case the $\chi^{2}$ value is only just significant at $P=0.05$, and in each case only a single cross yields usable data.

Two crosses used $L$. arcana females. The 1211 cross looked at $M p i$ : Pgm-2 linkage, and the arcana here was doubly homozygous. The 1625 cross looked at linkage between Pgm-1, Pgm-2 and Aat-1, and only for the Pgm-1 locus was the arcana heterozygous (as was the male saxatilis). Thus these crosses can justifiably be claimed to be looking at linkage in the saxatilis genome. 
Table 7 Summary of linkage studies. Cross numbers enabling particular pairwise linkage comparisons to be studied are given, and those where the linkage chi-square value is significant are indicated. See appendix for further details

\begin{tabular}{|c|c|c|c|c|c|c|c|c|c|}
\hline & $P g i$ & $P g m-1$ & $P g m-2$ & Aat-1 & Aat -2 & $A p-2$ & Lap-1 & $O d h$ & $I d h-2$ \\
\hline \multirow[t]{6}{*}{$M p i$} & 1072 & 1072 & 1135 & $1111 \dagger$ & \multirow[t]{6}{*}{2429} & \multirow[t]{6}{*}{1960} & \multirow[t]{6}{*}{ n.d. } & \multirow[t]{6}{*}{1918} & \multirow[t]{6}{*}{ n.d. } \\
\hline & 1114 & $1114^{*}$ & 1211 & 1625 & & & & & \\
\hline & 1686 & 1135 & 1625 & 2429 & & & & & \\
\hline & 1698 & 1625 & 1698 & & & & & & \\
\hline & $1918 \dagger$ & 1698 & 1960 & & & & & & \\
\hline & 2429 & & & & & & & & \\
\hline \multirow[t]{5}{*}{$P g i$} & & 1072 & 1072 & 1913 & \multirow[t]{5}{*}{2429} & \multirow[t]{5}{*}{ n.d. } & \multirow[t]{5}{*}{$1926^{*}$} & \multirow[t]{5}{*}{$1918^{*}$} & \multirow[t]{5}{*}{2451} \\
\hline & & 1698 & 1114 & 2429 & & & & & \\
\hline & & & 1698 & & & & & & \\
\hline & & & 1926 & & & & & & \\
\hline & & & 2451 & & & & & & \\
\hline \multirow[t]{5}{*}{$P g m-1$} & & & 1072 & 1625 & n.d. & n.d. & n.d. & n.d. & n.d. \\
\hline & & & 1114 & & & & & & \\
\hline & & & 1135 & & & & & & \\
\hline & & & 1625 & & & & & & \\
\hline & & & 1698 & & & & & & \\
\hline$P g m-2$ & & & & 1625 & n.d. & 1960 & 1926 & n.d. & 2451 \\
\hline Aat-1 & & & & & 2429 & n.d. & n.d. & $1952^{*}$ & n.d. \\
\hline Aat-2 & & & & & & n.d. & n.d. & n.d. & n.d. \\
\hline$A p-2$ & & & & & & & n.d. & n.d. & n.d. \\
\hline Lap-1 & & & & & & & & n.d. & n.d. \\
\hline Odh & & & & & & & & & n.d. \\
\hline
\end{tabular}

$* P=0.05-0.01$.

$\dagger P=0 \cdot 01-0.001$.

n.d. = no data.

\section{DISCUSSION}

Segregation of alleles at all 10 of the polymorphic loci examined ( $M p i$, Pgi, Pgm-1, Pgm-2, Aat-1, Aat-2, Ap-2, Lap-1, Odh, Idh-2) in Littorina saxatilis followed Mendelian expectations, and thus earlier genetic interpretations of gel patterns can be regarded as valid. Variants at an eleventh locus, purine nucleoside phosphorylase $(N p)$ have also been shown to segregate normally (Knight and Ward, 1986). If the ten loci described in the present paper are considered, 45 pairwise linkage comparisons are possible; at present we have data on 22 of these. Four pairs show some evidence of loose linkage, but further data are required to confirm these findings; none of the pairs showed any evidence of tight linkage. The two loci showing the strongest evidence of linkage are Aat-1 and $M p i$, but even here the results are not conclusive. Littorina saxatilis has a haploid count of 17 chromosomes (Janson, 1983), so the lack of evidence for strong linkage is not perhaps surprising. On the other hand, the a priori probability that all 10 of these loci are on separate chromosomes is low $(P=0.035)$.

Mallett et al., (1985) observed that at four of six loci screened in the progeny of the mussel, Mytilus edulis, the overall number of heterozygotes was significantly less than that expected from the parental genotypes. They proposed that genotypedependent larval mortality was the primary cause of the heterozygote deficits frequently observed in natural populations of this mollusc. Deviations from Hardy-Weinberg expectations are uncommon in L. saxatilis (Ward and Warwick, 1980; Janson and Ward, 1984), and, in the laboratory crosses detailed here, there are no indications of significant genotype-dependent larval mortality.

This paper also shows that female $L$. arcana will cross with male $L$. saxatilis, at least in the laboratory, and viable offspring are produced. However, attempts at carrying out the reciprocal cross have been unsuccessful. Although these two species have differing reproductive modes, saxatilis being ovoviparous and arcana oviparous, they are morphologically (Hannaford Ellis, 1979) and genetically (Ward and Warwick, 1980; Ward and Janson, 1985) closely related, with a genetic identity value of around $0 \cdot 95$. No diagnostic locus has yet been identified to facilitate study of the reproductive dynamics of these two species when sympatric, but the differences in gene frequency found in sympatric populations (Ward and Warwick, 1980; Ward and Janson, 1985) seem unlikely to result from physical or gametic barriers to the production of hybrids. We do not yet know whether hybrid individuals are sterile or fertile. 
Breeding experiments are continuing to investigate further enzyme loci, including the complex esterases, and animals of known linkage phase are being produced to act as parents in future generations. The genetics of shell morphology (colours,

\section{REFERENCES}

ADAMKEWICZ, L., TAUB, S. R. AND WALL, J. R. 1984. Genetics of the clam Mercenaria mercenaria. 1. Mendelian inheritance of allozyme variation. Biochem. Genet., 22, 215-219.

BEAUMONT, A. R., GOSLING, E. M., BEVERIDGE, C. M., BUDD, M. D. AND BURNELL, G. M. 1986. Studies on heterozygosity and size in the scallop, Pecten maximus (L.). In Gibbs, P. E. (ed.) Proc. 19th European Marine Biology Symposium, Cambridge University Press, pp. 443-454.

BERGER, E. M. 1977. Gene-enzyme variation in three sympatric species of Littorina II. The Roscoff population, with a note on the origin of North American L. littorea. Biol. Bull, 153, $255-264$.

BRUSSARD, P. F. AND McCRACKEN, G. F. 1974. Allczymic variation in a North American colony of Cepaea nemoralis. Heredity, 33, 98-101.

FRETTER, V. AND GRAHAM, A. 1980. The prosobranch molluscs of Britain and Denmark. J. Moll. Stud., suppl. 7.

HANNAFORD ELLIS, C. J. 1979. Morphology of the oviparous rough winkle, Littorina arcana Hannaford Ellis, 1978, with notes on the taxonomy of the $L$. saxatilis species-complex (Prosobranchia: Littorinidae). J. Conch., 30, 43-56.

HVILSOM, M. H. AND THEISEN, B. F. 1984. Inheritance of allozyme variations through crossing experiments with the blue mussel, Mytilus edulis L. Hereditas 101, 1-7.

JANSON, K. 1983. Chromosome number in two phenotypically distinct populations of Littorina saxatilis Olivi from the Swedish west coast. J. Moll. Stud., 49, 224-227.

JANSON, K. 1985. A morphologic and genetic analysis of Littorina saxatilis (Prosobranchia) from Venice, and on the problem of saxatilis-rudis nomenclature. Biol. J. Linn. Soc., 24, 51-59.

JANSON, K. AND WARD, R. D. 1984. Microgeographic variation in allozyme and shell characters in Littorina saxatilis Olivi (Prosobranchia: Littorinidae). Biol. J. Linn. Soc., 22, 289307. banding patterns, reticulations) are also being studied.

Acknowledgements Our thanks are due to the following people who kindly collected material, N. E. Buxton, D. S. Davis, J. Fair, K. Gilkinson, M. McAuley, R. O. M. Page. Part of this work was supported by research grant GR3/5319 from the Natural Environment Research Council to R. D. Ward.

JANSON, K. AND WARD, R. D. 1985. The taxonomic status of Littorina tenebrosa Montagu as assessed by morphological and genetic analyses. $J$. Conch., 32, 9-15.

JOHNSON, M. S. 1979. Inheritance and geographic variation of allozymes in Cepaea nemoralis. Heredity, 43, 137-141.

KNIGHT, A. J. AND WARD, R. D. 1986. Purine nucleoside phosphorylase polymorphism in the genus Littorina (Prosobranchia: Mollusca). Biochem. Genet., 24, 405-413.

MALLET, A. L., ZOUROS, E., GARTNER-KEPKAY, K. E., FREEMAN, K. R. AND DICKIE, L. M. 1985. Larval viability and heterozygote deficiency in populations of marine bivalves: evidence from pair matings of mussels. Mar. Biol., 87, 165-172.

MASTRO, E., CHOW, V. AND HEDGECOCK, D. 1982. Littorina scutulata and Littorina plena: sibling species status of two prosobranch gastropod species confirmed by electrophoresis. Veliger, 24, 239-246.

MOYSE, J., THORPE, J. P. AND AL-HAMADANI, E. 1982. The status of Littorina aestuarii Jeffreys: an approach using morphology and biochemical genetics. J. Conch., 31, 7-15.

OXFORD, G. S. 1975. Food induced esterase phenocopies in the snail Cepaea nemoralis, Heredity, 35, 361-370.

SNYDER, T. P. AND GOOCH, J. L. 1973. Genetic differentiation in Littorina saxatilis (Gastropoda). Mar. Biol, 22, 177-182.

WARD, R. D. AND JANSON, K. 1985. A genetic analysis of sympatric subpopulations of the sibling species Littorina saxatilis (Olivi) and Littorina arcana Hannaford Ellis. $J$. Moll. Stud., 51, 86-94.

WARD, R. D. AND WARWICK, T. 1980. Genetic differentiation in the molluscan species Littorina rudis and Littorina arcana (Prosobranchia: Littorinidae). Biol. J. Linn. Soc., $14,417-428$.

WARWICK, T. 1983. A method of maintaining and breeding members of the Littorina saxatilis (Olivi) species complex. J. Moll. Stud., 48, 368-370.

WILKINS, N. P. AND O'REGAN, D. 1980. Generic variation in sympatric sibling species of Littorina. Veliger, 22, 355-359. 


\section{APPENDIX}

Details of the breeding experiments enabling linkage comparisons to be made

\begin{tabular}{|c|c|c|c|c|c|c|c|c|}
\hline \multirow[b]{2}{*}{ Locus pair } & \multirow[b]{2}{*}{ Cross } & \multicolumn{3}{|c|}{ Number of progeny } & \multirow{2}{*}{$\begin{array}{l}\text { Linkage } \\
\text { chi (1 d.f.) }\end{array}$} & \multirow[b]{2}{*}{$r(\%)$} & \multicolumn{2}{|c|}{ Total } \\
\hline & & Total & A & B & & & chi & d.f. \\
\hline \multirow[t]{6}{*}{$P g i: M p i$} & 1072 & 70 & 38 & 32 & 0.514 & 一 & $9 \cdot 543$ & 7 \\
\hline & 1114 & 79 & 40 & 39 & 0.013 & - & $5 \cdot 962$ & 7 \\
\hline & 1686 & 32 & 19 & 13 & $1 \cdot 125$ & - & $1 \cdot 250$ & 3 \\
\hline & 1698 & 40 & 22 & 18 & 0.400 & - & $8 \cdot 000$ & 7 \\
\hline & 1918 & 162 & 99 & 63 & $8 \cdot 000 \dagger$ & $38 \cdot 9$ & $11 \cdot 778^{*}$ & 3 \\
\hline & 2429 & 53 & 31 & 22 & $1 \cdot 528$ & - & $1 \cdot 717$ & 3 \\
\hline \multirow[t]{2}{*}{ Pgi : Pgm-1 } & 1072 & 67 & 37 & 30 & 0.731 & - & $2 \cdot 313$ & 3 \\
\hline & 1698 & 16 & 8 & 8 & 0 & - & $0 \cdot 500$ & 3 \\
\hline \multirow[t]{5}{*}{ Pgi : Pgm-2 } & 1072 & 45 & 23 & 22 & 0.022 & - & $2 \cdot 467$ & 7 \\
\hline & 1114 & 80 & 41 & 39 & 0.050 & - & $6 \cdot 200$ & 7 \\
\hline & 1698 & 32 & 17 & 15 & 0.125 & - & $0 \cdot 750$ & 3 \\
\hline & 1926 & 87 & 47 & 40 & 0.563 & - & $3 \cdot 023$ & 7 \\
\hline & 2451 & 36 & 20 & 16 & 0.444 & - & 0.667 & 3 \\
\hline \multirow[t]{2}{*}{ Pgi: Aat-1 } & 1913 & 62 & 34 & 28 & 0.580 & - & $1 \cdot 871$ & 3 \\
\hline & 2429 & 54 & 31 & 23 & $1 \cdot 185$ & - & $4 \cdot 815$ & 3 \\
\hline Pgi:Aat-2 & 2429 & 50 & 31 & 19 & $2 \cdot 880$ & - & $3 \cdot 280$ & 3 \\
\hline Pgi: Lap-1 & 1926 & 17 & 13 & 4 & $4 \cdot 765^{*}$ & $23 \cdot 5$ & $4 \cdot 882$ & 3 \\
\hline Pgi:Odh & 1918 & 130 & 77 & 51 & $4 \cdot 431^{*}$ & $40 \cdot 8$ & $7 \cdot 046$ & 3 \\
\hline Pgi: Idh-2 & 2451 & 36 & 20 & 16 & 0.444 & - & 0.667 & 3 \\
\hline \multirow[t]{5}{*}{ Mpi : Pgm-1 } & 1072 & 69 & 38 & 31 & $0 \cdot 710$ & - & $2 \cdot 467$ & 7 \\
\hline & 1114 & 79 & 50 & 29 & $5 \cdot 582^{*}$ & $36 \cdot 7$ & $10 \cdot 215$ & 7 \\
\hline & 1135 & 43 & 23 & 20 & 0.209 & - & $1 \cdot 558$ & 3 \\
\hline & 1625 & 153 & 81 & 72 & 0.529 & - & 1.529 & 3 \\
\hline & 1698 & 15 & 8 & 7 & 0.067 & - & $10 \cdot 067$ & 7 \\
\hline \multirow[t]{5}{*}{$M p i: P g m-2$} & 1135 & 42 & 25 & 17 & $1 \cdot 524$ & - & $2 \cdot 381$ & 3 \\
\hline & 1211 & 99 & 54 & 45 & 0.818 & - & $2 \cdot 859$ & 3 \\
\hline & 1625 & 153 & 78 & 75 & 0.059 & - & $1 \cdot 170$ & 3 \\
\hline & 1698 & 31 & 16 & 15 & 0.032 & - & $9 \cdot 516$ & 7 \\
\hline & 1960 & 38 & 21 & 17 & $0 \cdot 381$ & - & $7 \cdot 053$ & 7 \\
\hline \multirow[t]{3}{*}{ Mpi: Aat-1 } & 1111 & 58 & 39 & 19 & $6 \cdot 897 \dagger$ & $32 \cdot 7$ & $10 \cdot 690$ & 7 \\
\hline & 1625 & 152 & 84 & 68 & $1 \cdot 68$ & - & $2 \cdot 632$ & 3 \\
\hline & 2429 & 54 & 32 & 22 & $1 \cdot 85$ & - & $4 \cdot 815$ & 3 \\
\hline Mpi:Aat-2 & 2429 & 51 & 31 & 20 & $2 \cdot 37$ & - & $3 \cdot 353$ & 3 \\
\hline$M p i: A p-2$ & 1960 & 41 & 21 & 20 & 0.024 & - & $2 \cdot 512$ & 7 \\
\hline Mpi: Odh & 1918 & 130 & 67 & 63 & 0.123 & - & 0.277 & 3 \\
\hline \multirow[t]{5}{*}{ Pgm-2: Pgm-2 } & 1072 & 44 & 24 & 20 & 0.364 & - & $4 \cdot 727$ & 3 \\
\hline & 1114 & 80 & 44 & 36 & 0.800 & - & $9 \cdot 600$ & 7 \\
\hline & 1135 & 42 & 25 & 17 & 1.524 & - & 1.619 & 3 \\
\hline & 1625 & 153 & 77 & 76 & 0.007 & - & $4 \cdot 856$ & 7 \\
\hline & 1698 & 16 & 9 & 7 & $0 \cdot 250$ & - & $1 \cdot 500$ & 3 \\
\hline Pgm-1:Aat-1 & 1625 & 152 & 84 & 68 & 1.684 & - & $7 \cdot 789$ & 7 \\
\hline Pgm-2:Aat-1 & 1625 & 152 & 82 & 70 & 0.947 & - & $2 \cdot 842$ & 3 \\
\hline$P g m-2: A p-2$ & 1960 & 50 & 25 & 25 & 0 & - & 0.400 & 3 \\
\hline$P g m-2: L a p-1$ & 1926 & 17 & 9 & 8 & 0.059 & - & $1 \cdot 588$ & 7 \\
\hline Pgm-2:Idh-2 & 2451 & 36 & 22 & 14 & 1.778 & - & $2 \cdot 000$ & 3 \\
\hline Aat-1: Odh & 1952 & 84 & 51 & 33 & $3.857^{*}$ & $39 \cdot 3$ & $4 \cdot 095$ & 3 \\
\hline Aat-1: Aat-2 & 2429 & 51 & 29 & 22 & 0.961 & - & $3 \cdot 039$ & 3 \\
\hline
\end{tabular}

$r=$ recombination fraction.

* $P=0.05-0.01$.

$\dagger P=0.01-0.001$. 